Published in Transportation Geotechnics 16 (2018) 51-62, accepted 2/7/18.

http://dx.doi.org/ 10.1016/j.trgeo.2018.07.001

\title{
Analysis of resonance effect for a railway track on a layered ground
}

\author{
J. -Y. Shih*, D.J. Thompson, E. Ntotsios
}

Institute of Sound and Vibration Research, University of Southampton, Southampton, SO17 1BJ, UK.

*: corresponding author; email: j.shih@bham.ac.uk

Now at: Birmingham Centre for Railway Research and Education, School of Engineering, University of Birmingham, Birmingham, B15 2TT, UK

\begin{abstract}
When a train runs on soft ground it can approach or even exceed the speed of surface waves in the ground. Under such conditions the amplitudes of the track response increase considerably. Moreover, a resonance-like phenomenon can occur in which a clear oscillation trail can be observed behind the moving axle loads. An investigation is presented of this resonance frequency and the critical speed effect for a track on a layered half-space subject to a moving load. Three different methods are used to investigate this resonance frequency: (i) the spectrum of the response to a moving load, (ii) analysis of the dispersion curves of the ground, and (iii) frequency analysis of the response to a stationary load. A parameter study is presented of a layered half-space ground with different P-wave speeds, S-wave speeds, and depth of the upper layer. The critical speeds are found in each case; in such a layered ground, the critical speed is greater than the Rayleigh wave speed of the soft upper layer due to the influence of the underlying half-space. The oscillating frequencies are shown to vary with the speed of the moving load, tending to reduce when the load speed increases. The P-wave speeds of both the upper layer and the underlying half-space are found to have negligible influence on the critical velocity and on the oscillating frequency; the S-wave speed of the half-space has only a small influence. Larger differences are found when the depth of the layer is varied. Finally, a formula for calculating this resonance frequency is proposed.
\end{abstract}

Keywords: critical speed, dispersion curve, layered half-space, resonance frequency, transfer function, oscillation trail 


\section{Introduction}

High-speed trains have become an important means of public transport due to their efficiency and relatively low impact on the environment. However, with increasing train speed, especially when the track alignment crosses soft ground, the track deflections increase dramatically as the train speed approaches the speed of surface waves in the soil [1,2]. Furthermore, when the speed of a load moving on a layered ground exceeds the Rayleigh wave speed of the upper layer, a resonance phenomenon is observed in which the track and ground surface behind the load oscillates with a certain frequency $[1,3-5]$. These phenomena were also found in the site measurements at Ledsgård in Sweden [6]. To avoid these effects, costly soil improvement or additional foundation structures may be required such as strengthening the embankment [7] or ground stabilisation using lime cement columns [8].

For an ideal homogeneous soil the critical speed is readily determined as the Rayleigh wave speed of the soil [9]. For a layered ground the phenomenon is more complex, but nevertheless a number of authors have investigated the critical speed effect and methods to evaluate it [9-14]. However, only limited attention has been given to the resonance-like phenomenon that occurs in some situations for a layered half-space.

Even in cases where the moving load speed is lower than the critical speed, significant vibration may occur that is associated with this resonance-like frequency, especially if it coincides with a strong excitation frequency from the train, for example due to the axle-passing frequencies [15]. Ground-borne vibration has become an important issue due to environmental concerns and, to give a correct assessment of the vibration levels occurring while train is passing, a numerical model that can correctly characterise the dynamic behaviour is required. Soil damping is an important factor for modelling the ground-borne vibration and in time domain models Rayleigh damping is commonly used for soil properties [12,16,17]. To apply the Rayleigh damping model, as used by Shih et al. [16], an appropriate 'dominant' frequency is required to select the corresponding damping coefficients. This is important not only to ensure the wave energy is sufficiently attenuated at the boundary of the model but also to represent the soil damping behaviour more correctly. Better understanding of this resonance phenomenon can thus lead to a more representative soil damping model and, together with the appropriate excitation mechanisms, to a better assessment for the ground-borne vibration.

Wave propagation in a homogeneous half-space is non-dispersive and consequently no resonance frequency is found for a moving point source [16]. In contrast, a resonance frequency can be found for layered half-space soil. This resonance frequency is usually identified with the 'cut-on 
frequency' of the upper layer, above which the waves begin to propagate in the upper soil layer [18]. It is indicated in the literature that the resonance frequency is related to the depth of the layer and the P-wave speed in the first layer [17-19]. A modified formula, based on the shear wave speed of the first layer and its depth with a cut-off factor, was introduced by Mehzer et al. [12]. However, the effect of load motion, which may modify the frequency, is not discussed in these papers.

In this paper an investigation is carried out into this resonance phenomenon and its dependence on the properties of a layered ground. This analysis is carried out by using a three-dimensional semianalytical method [1,5]. This model is based on the formulation of Haskell and Thomson [20,21] and uses a two-dimensional Fourier transform over the axial and transverse coordinates to represent the layered ground in terms of the corresponding wavenumbers. The track is represented by a layered beam structure coupled to the ground over a finite-width strip. A static or moving load can be considered which may be either constant or harmonically varying.

Herein three different methods are used to study this resonance frequency for a track on a layered half-space. First, the semi-analytical method presented in [5] is used to calculate the rail receptance due to a stationary harmonic load applied on the rail. Second, a quasi-static load moving along the track is considered using the same model as in [1]. The frequency spectra of the response in the non-moving frame due to the moving load are obtained and used to identify the resonance frequency. Third, following the method in [10], dispersion curves from the layered half-space with and without the track are calculated and used to estimate the resonance frequency for different load speeds by finding the intersection points between the dispersion curves and the load speed line.

Results are presented for a layered half-space in which various values are considered for the depth of the upper ground layer and the P- and S-wave speeds of the layer and the substratum; results are also compared with those for a homogeneous half-space. In all cases the upper layer is considered to be softer than the underlying half-space, as is commonly found in practice. The critical speed is determined first for each case from the semi-analytical model. Then the resonance frequency is assessed using the three different methods and the results are compared. Finally, the results from the above methods are compared with the results from the formulae indicated in $[12,17,18]$ and a revised formula is proposed.

\section{Parameters used in the study}

A range of different cases are introduced here for a ground with a single soft layer above a stiffer half-space. The parameters defining these cases are listed in Table 1. These are the P-, and S-wave speeds for the upper layer and the underlying half-space, as well as the depth of the first layer. The $\mathrm{S}$-wave speed of the upper layer is kept fixed at $60 \mathrm{~m} / \mathrm{s}$ and the other wave speeds are varied 
relative to this. The soil density is set to $2000 \mathrm{~kg} / \mathrm{m}^{3}$ throughout. The damping is represented by a constant damping loss factor of 0.05 in each case.

The chosen reference soil properties for the upper layer corresponds to very soft soil, which approximately represents a typical soft clay. Although in such a situation the soil may have a high water content, the main focus of the present work is to look generically at how the wave speeds of the soil influence the dynamic behaviour of the layered ground. The wave speeds have therefore been chosen somewhat arbitrarily for convenience in the parametric analysis. The actual values of, for example, the mass density are less important for the present study.

In the initial case, the $\mathrm{P}$-wave speed of the upper layer is set to $120 \mathrm{~m} / \mathrm{s}$ and the $\mathrm{P}$ - and $\mathrm{S}$-wave speeds of the substratum are assumed to be double the values in the upper layer. This case is used as the reference case for comparison with the others. In cases 2 and 3, the P-wave speeds of the two layers are varied whereas in cases 4 and 5, the $S$-wave speed of the underlying half-space is varied while keeping the P-wave speed equal to twice the value of the S-wave speed. In cases 6 and 7, the layer depth is varied while keeping the same wave speeds as case 1. The homogeneous half-space (case 8) is an extreme case with an infinitely deep upper layer.

Table 1 Parameters used to define the ground

\begin{tabular}{|c|c|c|c|c|c|c|}
\hline No. & $\begin{array}{c}\text { layer depth, } \\
H(\mathrm{~m})\end{array}$ & $\begin{array}{c}\text { 1st layer } \\
\text { P-wave, } c_{p 1} \\
(\mathrm{~m} / \mathrm{s})\end{array}$ & $\begin{array}{c}\text { 1st layer } \\
\text { S-wave, } c_{s 1} \\
(\mathrm{~m} / \mathrm{s})\end{array}$ & $\begin{array}{c}\text { 2nd layer } \\
\text { P-wave, } c_{p 2} \\
(\mathrm{~m} / \mathrm{s})\end{array}$ & $\begin{array}{c}\text { 2nd layer } \\
\text { S-wave, } c_{s 2} \\
(\mathrm{~m} / \mathrm{s})\end{array}$ & $\begin{array}{c}\text { Critical } \\
\text { speed, } V_{c r} \\
(\mathrm{~m} / \mathrm{s})\end{array}$ \\
\hline 1 & 2 & 120 & 60 & 240 & 120 & 79 \\
\hline 2 & 2 & 240 & 60 & 240 & 120 & 80 \\
\hline 3 & 2 & 240 & 60 & 480 & 120 & 80 \\
\hline 4 & 2 & 240 & 60 & 480 & 240 & 82 \\
\hline 5 & 2 & 120 & 60 & 170 & 85 & 70 \\
\hline 6 & 4 & 120 & 60 & 240 & 120 & 62 \\
\hline 7 & 8 & 120 & 60 & 240 & 120 & 57 \\
\hline 8 & $\infty$ & 120 & 60 & - & - & 55 \\
\hline
\end{tabular}

The track properties used in each case are listed in Table 2 and are largely based on the ballasted track used in [22]. The value for the rail pad stiffness is equivalent to a stiffness of $300 \mathrm{MN} / \mathrm{m}$ per pad, which corresponds to a medium stiffness rail pad. In the current model, the railway track is considered as a straight ballasted track at the surface of the layered elastic half-space, as shown in Fig. 1(a). Linear dynamic behaviour is assumed throughout. The track is considered invariant in the longitudinal $(x)$ direction and is modelled as a beam supported by vertical springs representing the rail pads, a layer of mass representing the sleepers and a further layer of springs with consistent 
mass representing the ballast, as shown in Fig. 1(b). Since each axle load is distributed equally between the two rails, a single beam is used to represent both rails.

Table 2 Track properties (for two rails)

\begin{tabular}{|c|c|c|}
\hline Parameter & Value & Units \\
\hline Rail mass & 120 & $\mathrm{~kg} / \mathrm{m}$ \\
\hline Rail bending stiffness & $1.28 \times 10^{7}$ & $\mathrm{Nm}^{2}$ \\
\hline Rail damping loss factor & 0.01 & \\
\hline Railpad stiffness per unit track length & $1.0 \times 10^{9}$ & $\mathrm{~N} / \mathrm{m}^{2}$ \\
\hline Railpad damping loss factor & 0.1 & \\
\hline Sleeper mass per unit track length & 541.8 & $\mathrm{~kg} / \mathrm{m}$ \\
\hline Ballast stiffness per unit track length & $4.64 \times 10^{9}$ & $\mathrm{~N} / \mathrm{m}^{2}$ \\
\hline Ballast mass per unit track length & 1740 & $\mathrm{~kg} / \mathrm{m}$ \\
\hline Ballast damping loss factor & 0.04 & \\
\hline Ballast width at the bottom & 3.2 & $\mathrm{~m}$ \\
\hline
\end{tabular}

The model is formulated in the wavenumber-frequency domain and uses the transfer function matrices for the ground formulated in [5] and [1] in a frame of reference moving with the loads. For the calculation of the response in the wavenumber domain, equally-spaced wavenumbers are used for the directions both parallel and normal to the track. In each direction the maximum wavenumber is set to $10 \pi \mathrm{rad} / \mathrm{m}$ and the number of wavenumber points in each direction is set to be 2048 . The inverse Fourier transform is carried out using the FFT algorithm in order to transform the response from the wavenumber to the space doamain. The maximum wavenumber and the wavenumber discretization define spatial resolution and the sizer of the spatial domain and are chosen to ensure an efficient and sufficiently accurate Fourier transform.

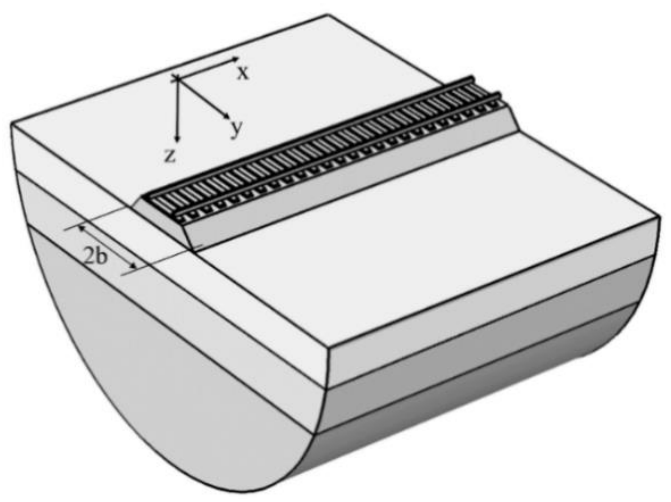

(a)

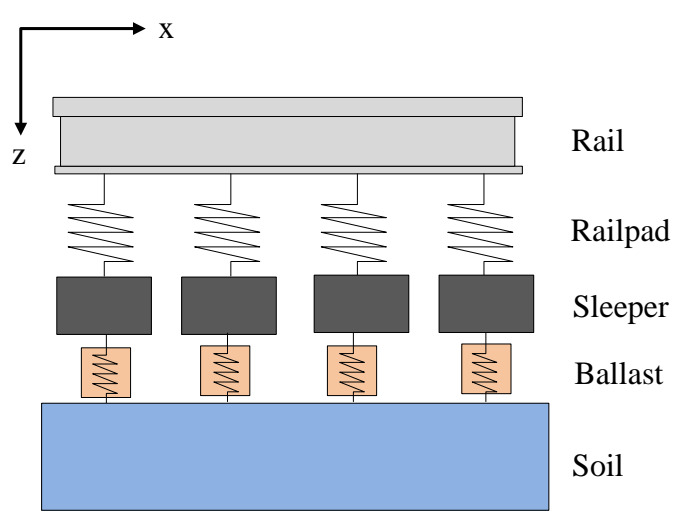

(b)

Figure 1 (a) The geometry of the track ground system; (b) beam-spring-mass representation of the ballasted track form 


\section{Investigation of the critical speed}

To determine the critical speed, the maximum displacement on the track induced by a moving point load is calcuated by using the three-dimensional semi-analytical track/ground model of [1]. The results for the various parameter sets are shown in Fig. 2.

As shown in Fig. 2(a), compared with case 1, the maximum displacement is reduced at all speeds by around $18 \%$ when the P-wave speed of the first layer is doubled (case 2). Almost the same results are found when additionally the P-wave speed of the second layer is doubled (case 3). When both the P-wave speed and S-wave speed of the underlying layer are increased as well as the P-wave speed of the upper layer (case 4) the deflection reduces by about $30 \%$ compared with case 1 . However, the critical speed found in these four cases remains almost the same, as shown in Table 1. The critical speed only increases slightly when the S-wave speed of the underlying half-space is additionally increased (case 4).

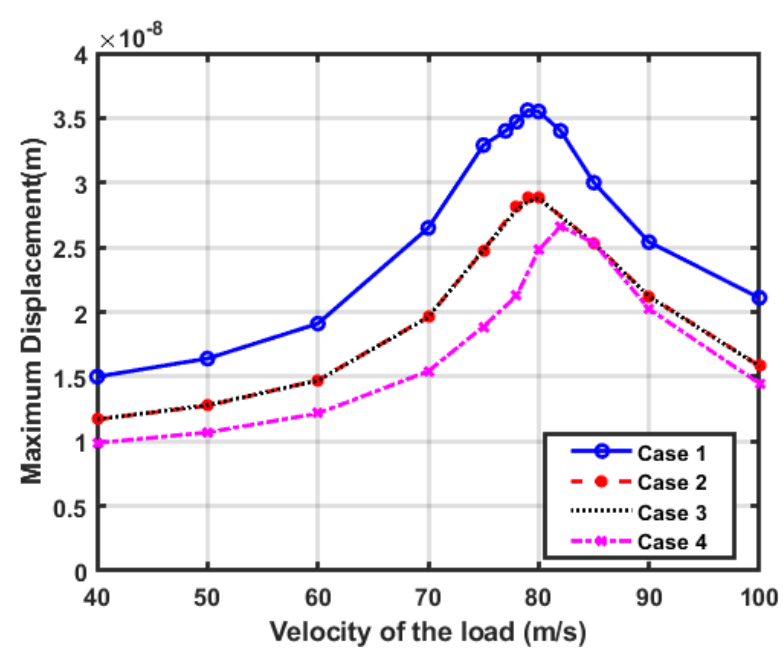

(a)

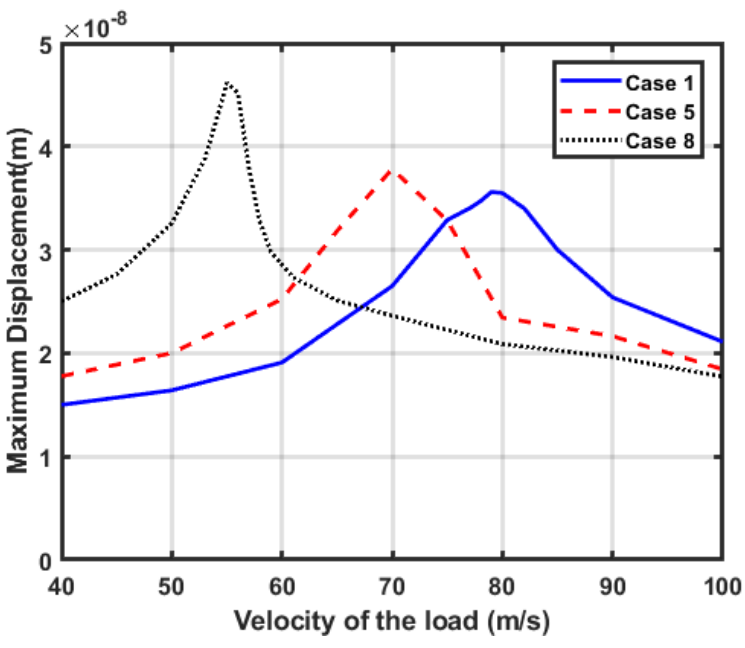

(b)

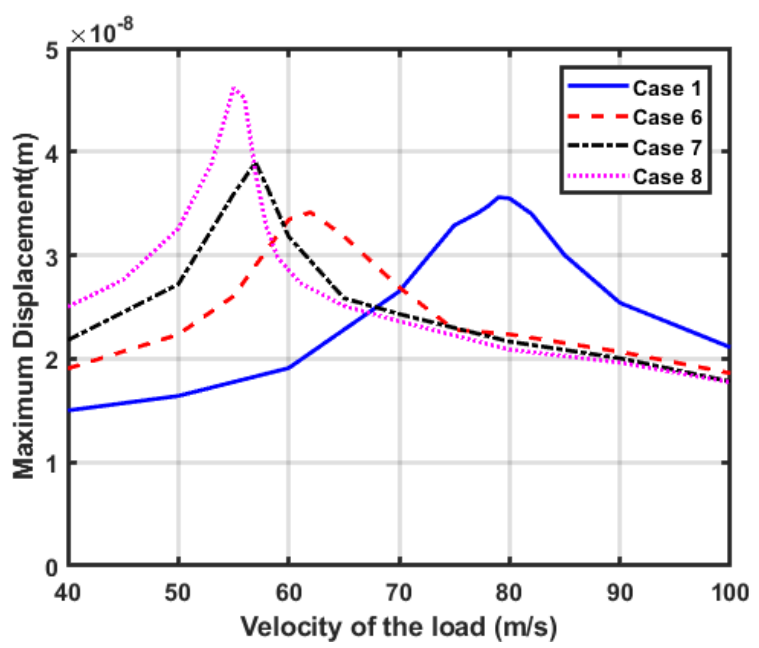

(c) 
Figure 2 Maximum displacement as a function of load speed for different cases; (a) variation of $c_{p 1}$ and $c_{p 2} ;(\mathrm{b})$ variation of $c_{s 2} ;$ (c) variation of layer depth

Fig. 2(b) shows the influence of changing the S-wave speed of the underlying half-space. The critical speed changes from $79 \mathrm{~m} / \mathrm{s}$ to $70 \mathrm{~m} / \mathrm{s}$ when the $S$-wave speed of the second layer is reduced from $120 \mathrm{~m} / \mathrm{s}$ to $85 \mathrm{~m} / \mathrm{s}$ (case 5). Reducing it further to $60 \mathrm{~m} / \mathrm{s}$ (i.e. the same properties as the upper layer) produces a homogeneous half-space, for which the critical speed is found to be $55 \mathrm{~m} / \mathrm{s}$. Thus, significant differences in critical speed are found when the shear wave speed of the lower layer is changed. Moreover, the displacement at the critical speed is increased as the soil becomes softer.

Fig. 2(c) shows the effect of varying the depth of the first layer. Here also the critical speed tends to decrease and the maximum deflection tends to increase as the layer depth is increased.

\section{Investigation of the resonance frequency for layered half-space}

Assessments of the resonance frequency based three different methods are presented and discussed here.

\subsection{Responses to a stationary harmonic load}

The response due to a stationary harmonic load acting on the rails is shown in Fig. 3 in the form of the point receptance. At low frequency this is stiffness-controlled before rising to a peak at the first resonance frequency. This occurs at around $10 \mathrm{~Hz}$ for cases 1 to 5, which have the same layer depth but different wave speeds for the ground. On the other hand, the resonance frequency decreases when the depth of the layer is increased, as seen for cases 6 and 7, and eventually no clear peak can be found for the homogeneous half-space (case 8). A second resonance frequency occurs at around $40 \mathrm{~Hz}$ in all cases. However, the receptance becomes much lower than at the first resonance frequency. As a result, the investigation focusses on the first resonance frequency. The resonance frequencies found in these seven cases from the peaks in the receptance are listed in Table 3 . They will be compared with results from the other methods in Section 4.4 below.
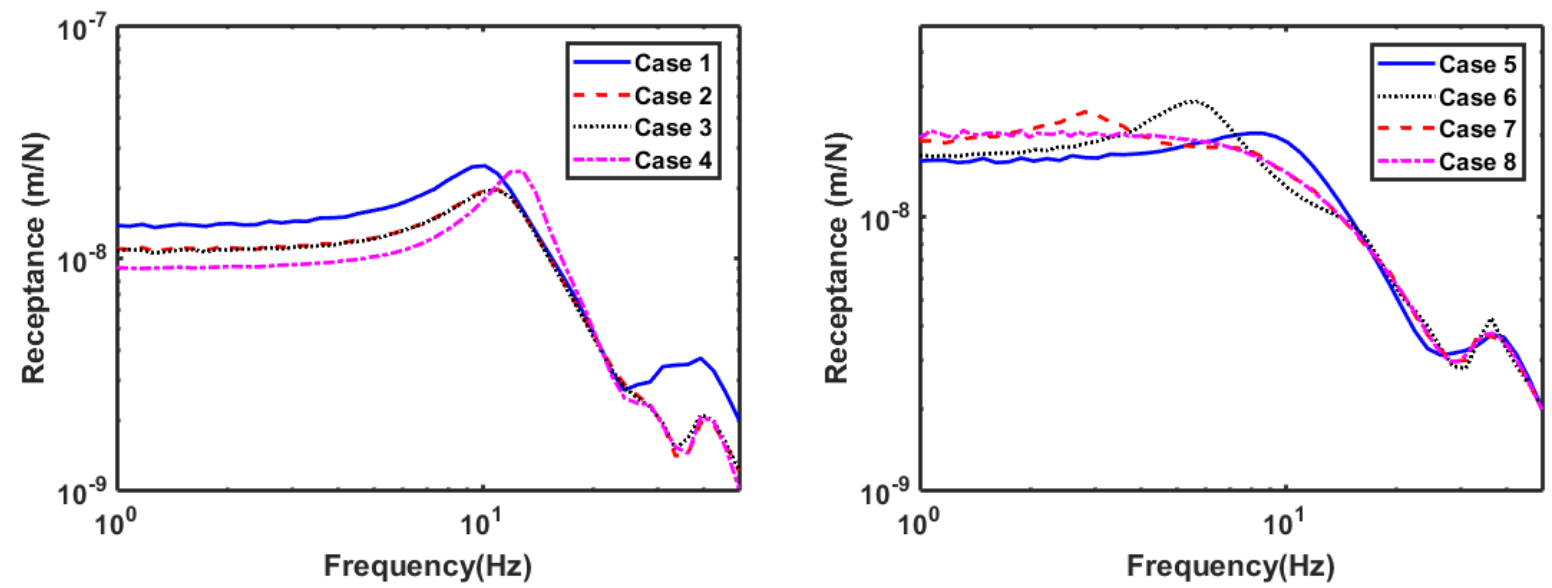
Figure 3 Receptance of the rail from eight different cases listed in Table 1; (a) cases 1 4; (b) cases $5 \sim 8$

Table 3 The resonance frequencies found in seven cases of layered ground (Table 1) for a stationary harmonic load

\begin{tabular}{|c|c|}
\hline & Resonance frequencies \\
\hline Case 1 & $10 \mathrm{~Hz}$ \\
\hline Case 2 & $11 \mathrm{~Hz}$ \\
\hline Case 3 & $11 \mathrm{~Hz}$ \\
\hline Case 4 & $13 \mathrm{~Hz}$ \\
\hline Case 5 & $9 \mathrm{~Hz}$ \\
\hline Case 6 & $6 \mathrm{~Hz}$ \\
\hline Case 7 & $3 \mathrm{~Hz}$ \\
\hline
\end{tabular}

\subsection{Responses from moving point load}

In this section, the semi-analytical model of [1] is used to predict the response to a moving constant load. The results are calculated in the moving frame but they are transformed to the non-moving frame. Results are presented as time histories and the corresponding frequency spectra of the response for a number of speeds in each case, both below and above the critical speed.

Figure 4 presents the results for case 1, which has a critical speed of $79 \mathrm{~m} / \mathrm{s}$. A significant peak can be found between 10 and $15 \mathrm{~Hz}$ for load speeds between $70 \mathrm{~m} / \mathrm{s}$ and $80 \mathrm{~m} / \mathrm{s}$ with the peak frequency tending to decrease with increasing speed. This can also be seen as a clear oscillation in the displacement time histories in Fig. 4(b). The resonance phenomenon can thus be observed for load speeds 70 and $75 \mathrm{~m} / \mathrm{s}$, which are lower than the critical speed. However, there is no clear peak in the spectrum or oscillation in the time domain for load speeds lower than $70 \mathrm{~m} / \mathrm{s}$. The time-domain results for $60 \mathrm{~m} / \mathrm{s}$ (not shown) contain no oscillation after the load.

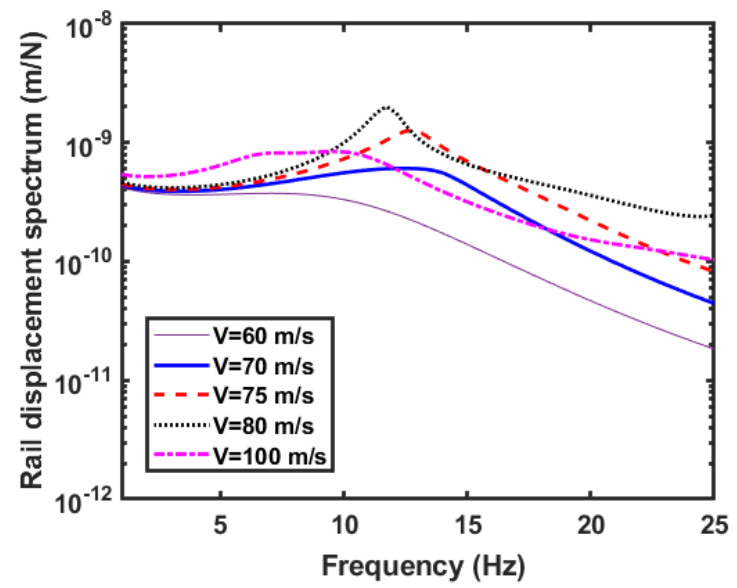

(a)
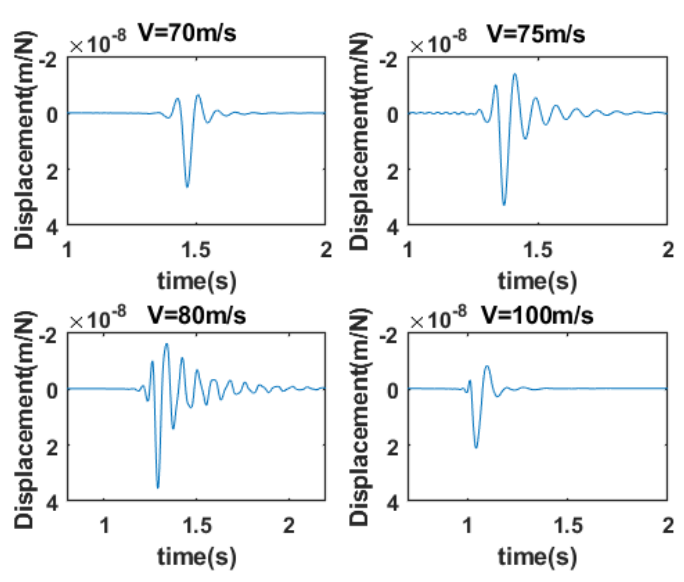

(b) 
Figure 4 Results from case 1 for different load speeds; (a) rail displacement spectrum; (b) rail displacement in the time domain

The results from cases 2 4, which have similar critical speeds of 80-82 m/s, are shown in Figs 5 to 7. These show similar trends with a clear peak between 10 and $15 \mathrm{~Hz}$ for speeds higher than $75 \mathrm{~m} / \mathrm{s}$, which tends to shift to a slightly lower frequency as the load speed increases further. The resonance peak at $75 \mathrm{~m} / \mathrm{s}$ tends to become less clear with a stiffer substratum while the peak at $70 \mathrm{~m} / \mathrm{s}$ disappears. Conversely, for a load speed of $100 \mathrm{~m} / \mathrm{s}$ the oscillation tends to become longer and the peak in the spectrum clearer, as seen in Fig. 7.

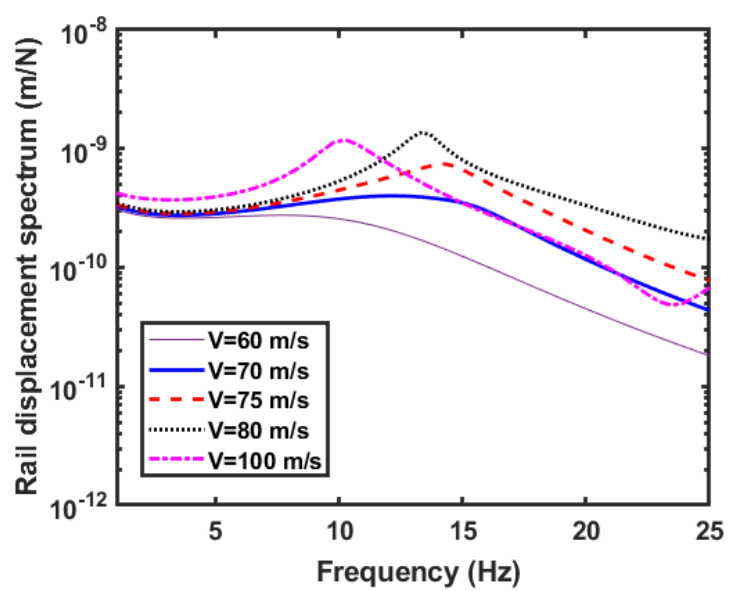

(a)
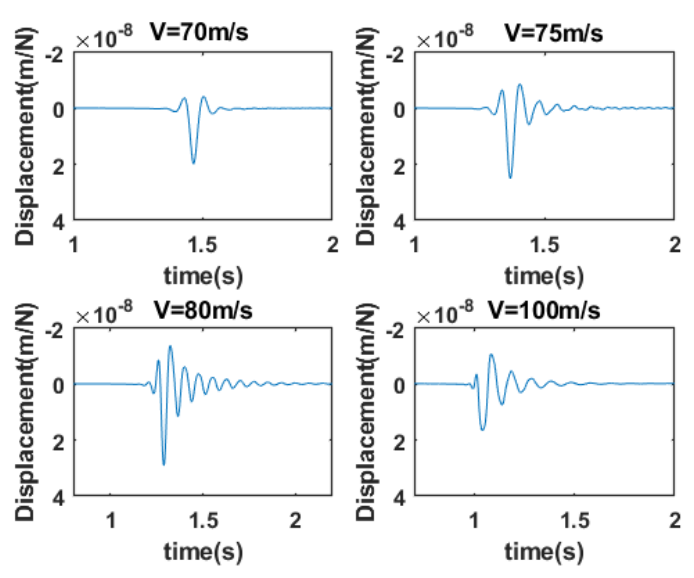

(b)

Figure 5 Results from case 2, with increased $c_{p 1}$, for different load speeds; (a) rail displacement spectrum; (b) rail displacement in the time domain

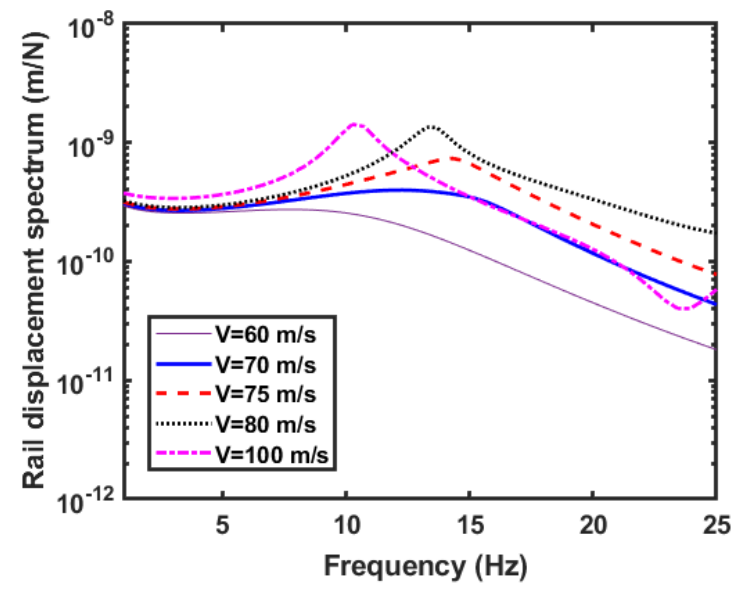

(a)
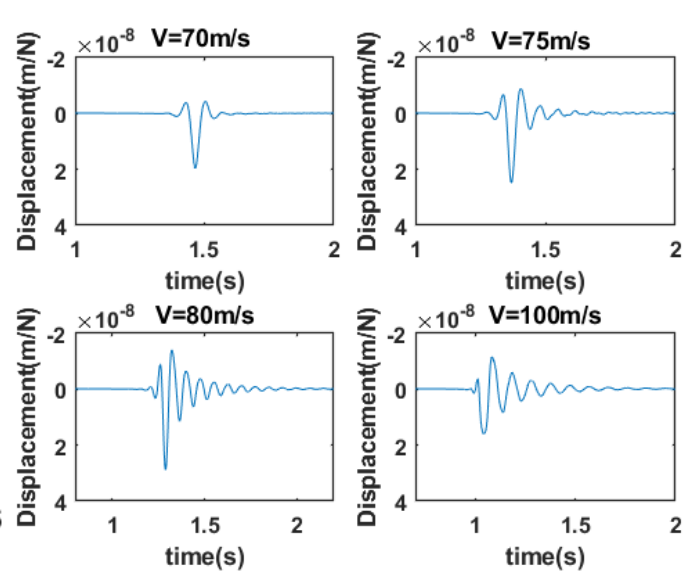

(b)

Figure 6 Results from case 3, with increased $c_{p 1}$ and $c_{p 2}$, for different load speeds; (a) rail displacement spectrum; (b) rail displacement in the time domain 


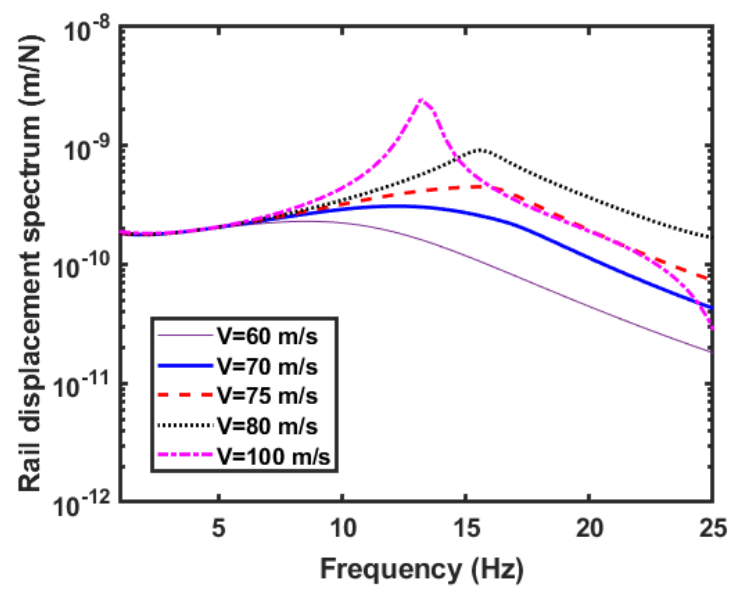

(a)
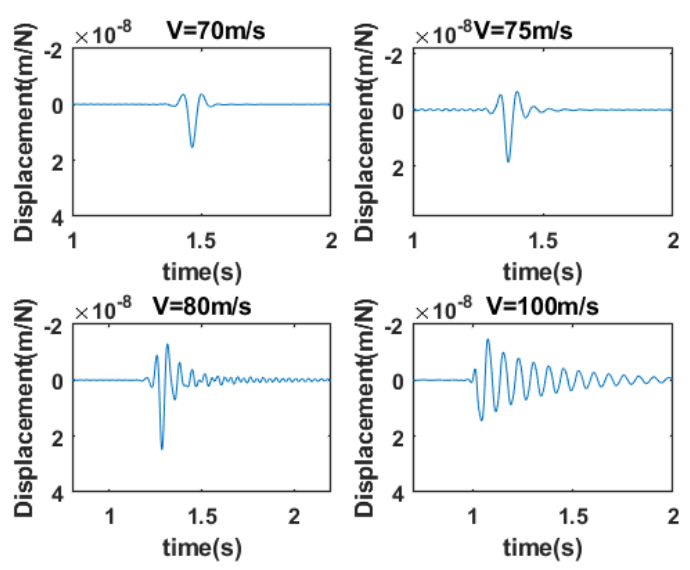

(b)

Figure 7 Results from case 4 , with increased $c_{p 1}, c_{p 2}$ and $c_{s 2}$, for different load speeds; (a) rail displacement spectrum; (b) rail displacement in the time domain

Figure 8 shows the results for case 5 , which has a lower $\mathrm{S}$-wave speed for the underlying soil than case 1 . In this case there is only a clear peak in the spectrum for a speed of $70 \mathrm{~m} / \mathrm{s}$, which corresponds to the critical speed. Similarly, in the time domain response there is only a clear oscillation at the critical load speed of $70 \mathrm{~m} / \mathrm{s}$.

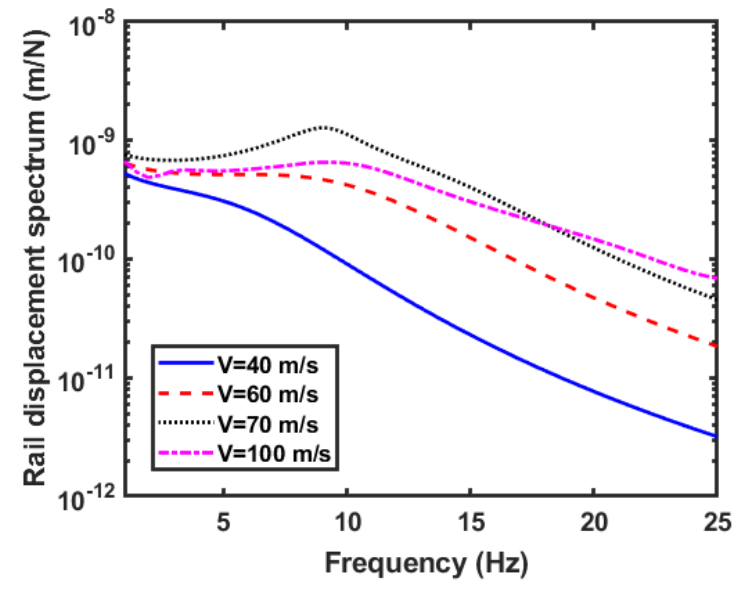

(a)
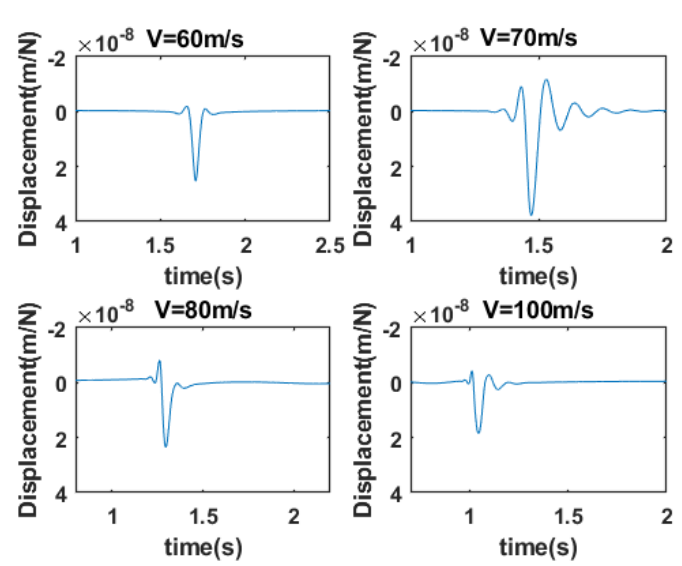

(b)

Figure 8 Results from case 5, with reduced $c_{p 2}$ and $c_{s 2}$, for different load speeds; (a) rail displacement spectrum; (b) rail displacement in the time domain

The results for cases 6 and 7, which have a deeper surface layer and critical speeds of 62 and $57 \mathrm{~m} / \mathrm{s}$, are shown in Figs 9 and 10. A clear resonance peak can be found for both cases when the load speed is higher than $60 \mathrm{~m} / \mathrm{s}$. It decreases in frequency when the depth of the first layer is increased, occurring between around 7 and $9 \mathrm{~Hz}$ for case 6 and between 3 and $6 \mathrm{~Hz}$ for case 7 . The resonancelike phenomenon can be found again for case 6 in Fig. 9(b) for $60 \mathrm{~m} / \mathrm{s}$, which is lower than the critical speed. However, unlike other cases (except case 8), where a clear oscillation tail can be 
observed for speeds lower than the critical speed, in case 7 the resonance phenomenon only occurs when the load speed is equal to or higher than the critical speed, as shown in Fig. 10(b).

The corresponding results from the homogeneous half-space are shown in Fig. 11. The resonance phenomenon cannot be identified in either the spectrum or the time domain results.

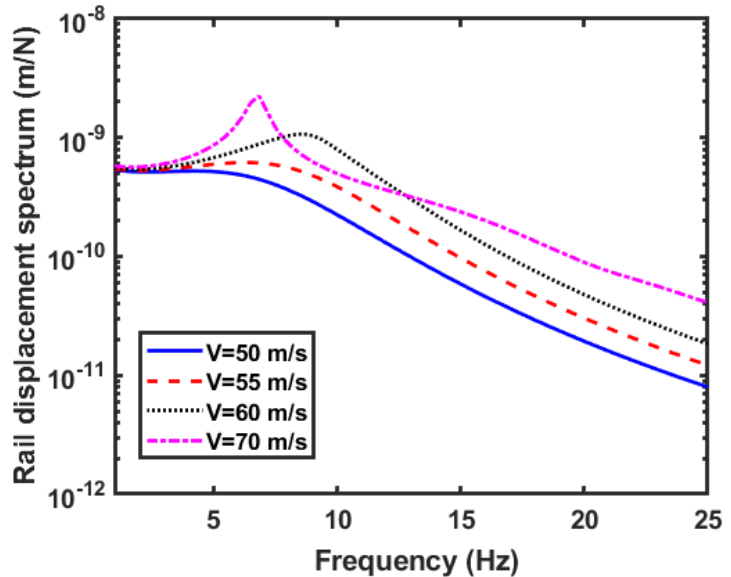

(a)
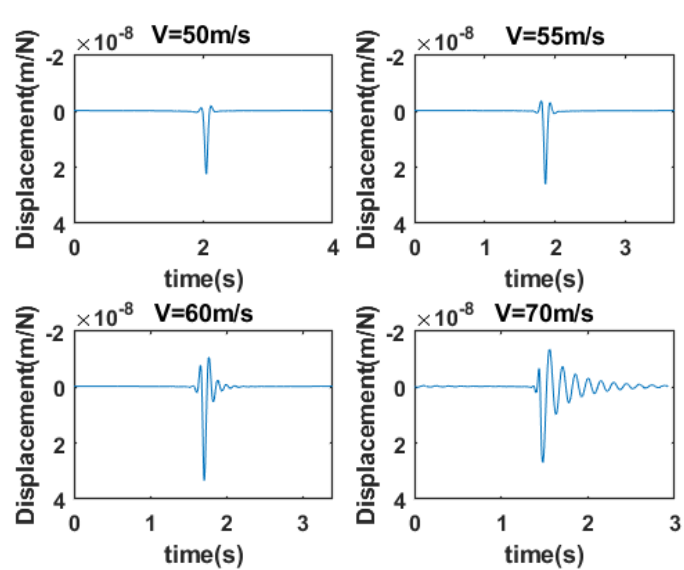

(b)

Figure 9 Results from case 6, with increased layer depth of $4 \mathrm{~m}$, for different load speeds; (a) rail displacement spectrum; (b) rail displacement in the time domain

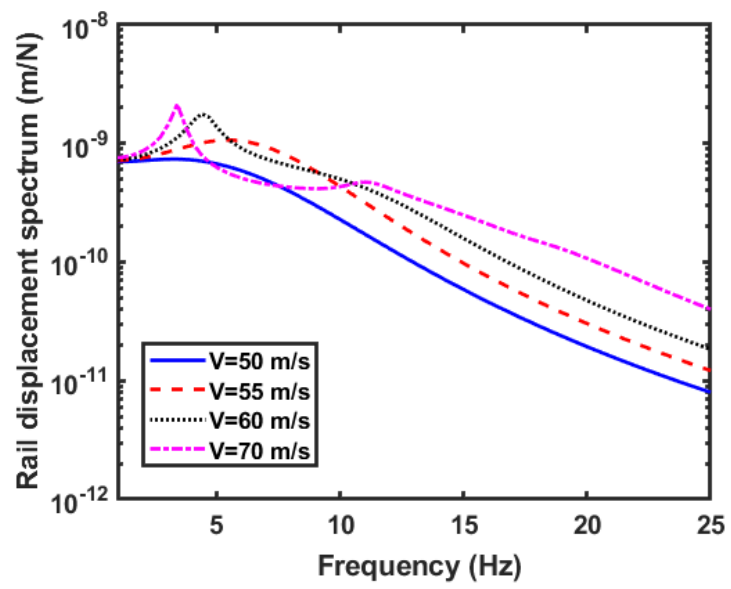

(a)
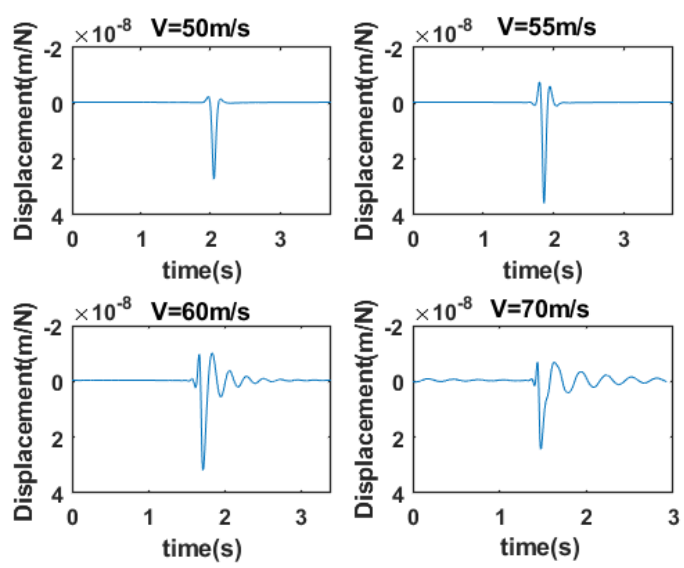

(b)

Figure 10 Results from case 7, with increased layer depth of $8 \mathrm{~m}$, for different load speeds; (a) rail displacement spectrum; (b) rail displacement in the time domain 


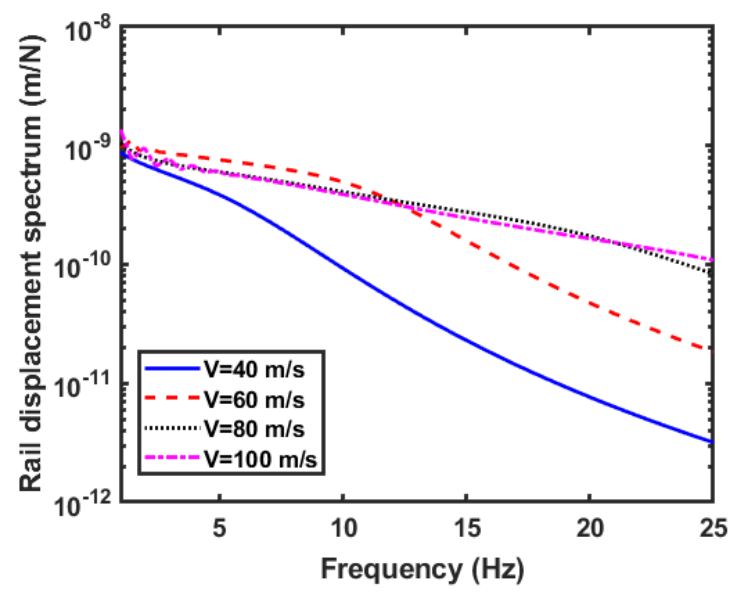

(a)
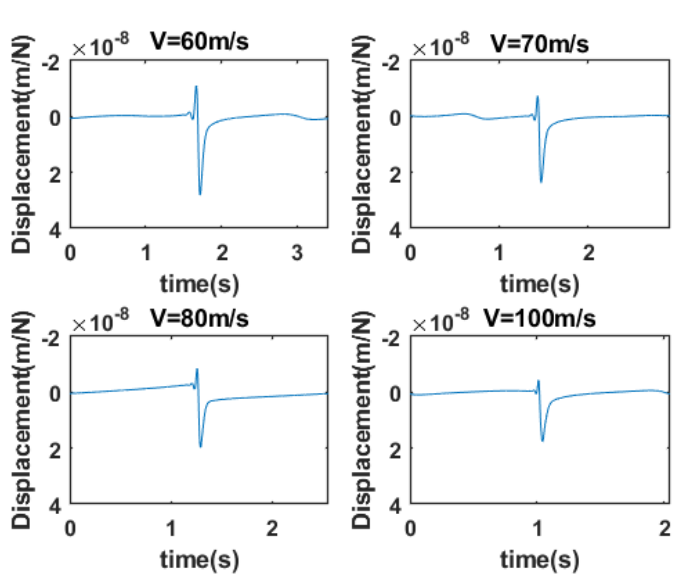

(b)

Figure 11 Results from case 8 (homogeneous half-space) for different load speeds; (a) rail displacement spectrum; (b) rail displacement in the time domain

\subsection{Dispersion curves}

In this section, using the method introduced by Sheng et al. [10], the ground dispersion curves are used to identify the dominant frequency of the response. This method was also recently used by Costa et al. to assess the critical speed [9]. Fig. 12 shows the dispersion results for case 1. The lefthand graph shows the dispersion diagram for the layered ground without track, which can be obtained from the analytical model. This shows the coupled compressional and vertically-polarised shear (P-SV) waves. The propagating wave modes in the ground without track are represented by the solid lines and two dashed lines represent the Rayleigh wave speed of the top layer (upper line) and the shear wave speed of the underlying half-space (lower line). The line corresponding to the critical speed $(79 \mathrm{~m} / \mathrm{s})$ is also shown. To account for the influence of the track, the right-hand graph shows a colour contour plot of the vibration amplitude excited by a stationary oscillating vertical force on the track as a function of wavenumber in the ground at each frequency. The results shown in the figure are based on the response at the ground surface, directly beneath the track, the wavenumber being in the direction of the track. The first propagating mode from the free field without consideration of the track is superimposed for comparison. 


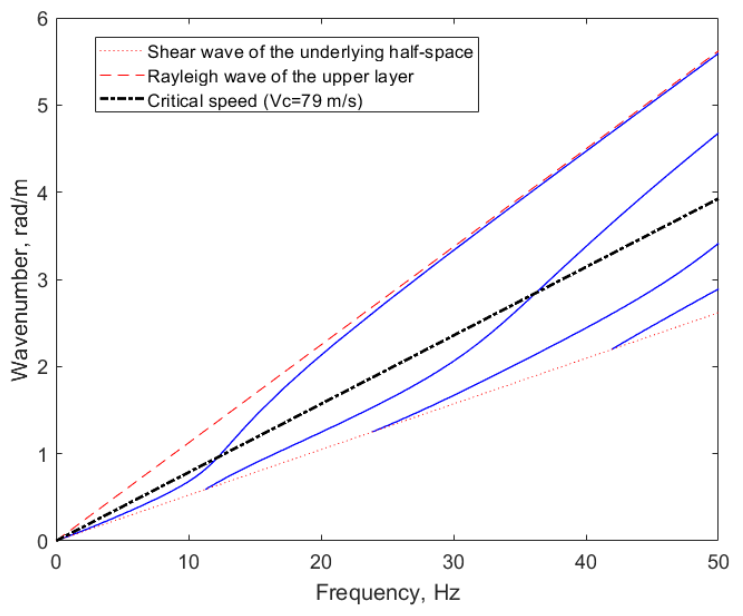

(a)

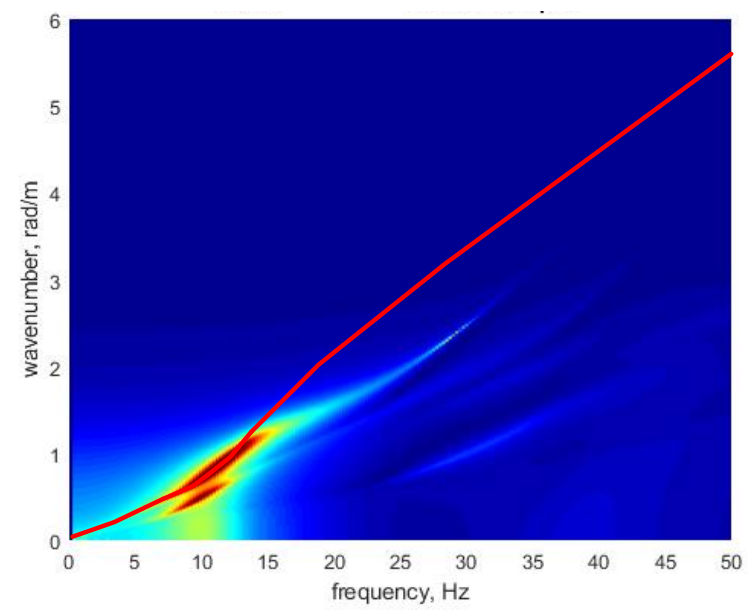

(b)

Figure 12 Dispersion diagrams obtained from analytical model for case 1; (a) without track; (b) with track

As shown in Fig. 12(b), at higher frequency the wavenumber results obtained without the track are higher than the results including the track. This is due to the fact that the track is stiffer than the ground. However, below about $15 \mathrm{~Hz}$ the two results are very similar. A similar conclusion was reached by Costa et al. [9] who compared the dispersion curve from three different representative track models with the results without the track. According to Sheng et al. [1], the resonance frequency induced by a moving point load can be found from the intersection point between the load speed line and the propagating mode dispersion curves. As the dispersion results are similar with or without the track in this low frequency region, the intersection with the result without the track can be used as an approximation. The corresponding intersection point occurs in this case at around $12 \mathrm{~Hz}$, see Fig. 11(a). As the load speed increases, the intersection point will shift to a slightly lower frequency.

Very similar results are found for cases 2 and 3 in Fig. 13. This is because the wavenumbers of the propagating waves lie between the Rayleigh wavenumber of the upper layer material and the shear wavenumber of the lower layer material and they rise from the wavenumber of the lower layer to that of the upper layer at around the cut-on frequency of the upper layer [18]. As a result, only very small differences are found in the dispersion curves when the P-wave speeds of the first or second layer are varied.

Larger differences are found when the S-wave speed is changed, as shown in Fig. 14 for cases 4 and 5. Nevertheless, a similar insertion point is found for case 4, as shown in Fig. 14(a), due to the fact that the surface wave of the upper layer remains the same as in the previous cases. On the other hand, the intersection point drops to around $10 \mathrm{~Hz}$ when both the shear wave speed and 
compressional wave speed of the substratum are reduced, as shown in Fig. 14(b). Furthermore, the wave propagation modes in case 5 tend to become less dispersive due to the fact that the two layers have more similar material properties.

Figure 15 shows the corresponding results for cases 6 and 7 in which the depth of the first layer is increased. Here the wavenumber increases towards the Rayleigh wavenumber of the upper layer at a lower frequency, causing the intersection with the load speed line to occur at a lower frequency, 9 $\mathrm{Hz}$ for case 6 and $7 \mathrm{~Hz}$ for case 7.

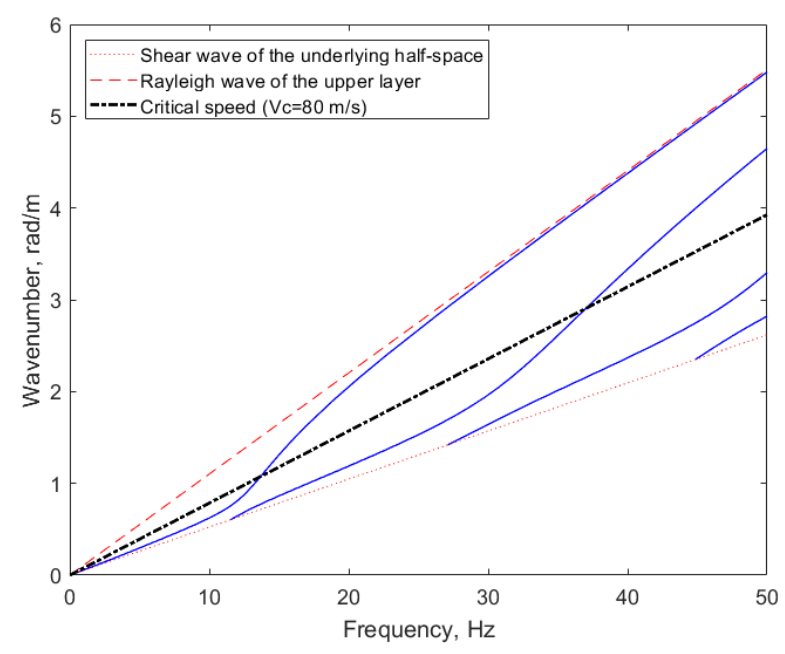

(a)

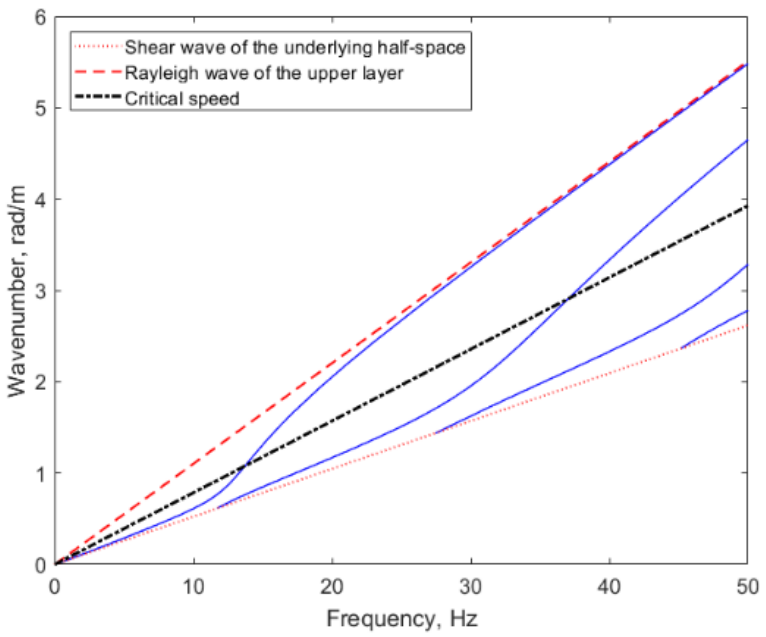

(b)

Figure 13 Dispersion diagrams for (a) case $2\left(c_{p 2}=240 \mathrm{~m} / \mathrm{s}\right)$; (b) case $3\left(c_{p 2}=480 \mathrm{~m} / \mathrm{s}\right)$

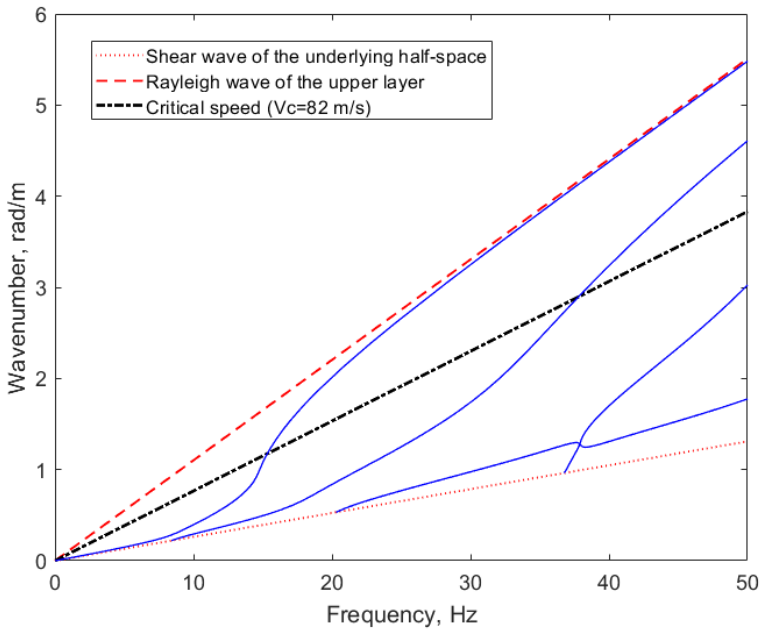

(a)

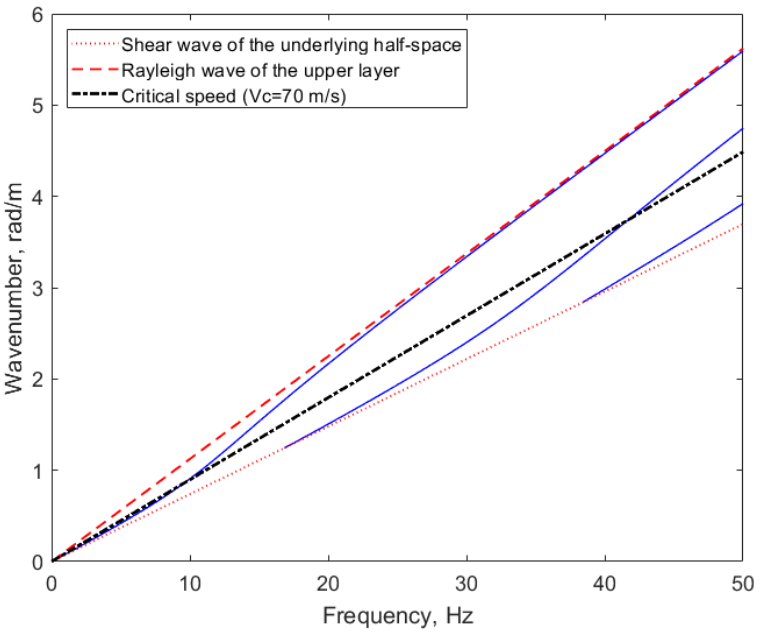

(b)

Figure 14 Dispersion diagrams for (a) case $4\left(V_{c r}=82 \mathrm{~m} / \mathrm{s}\right)$; (b) case $5\left(V_{c r}=70 \mathrm{~m} / \mathrm{s}\right)$ 


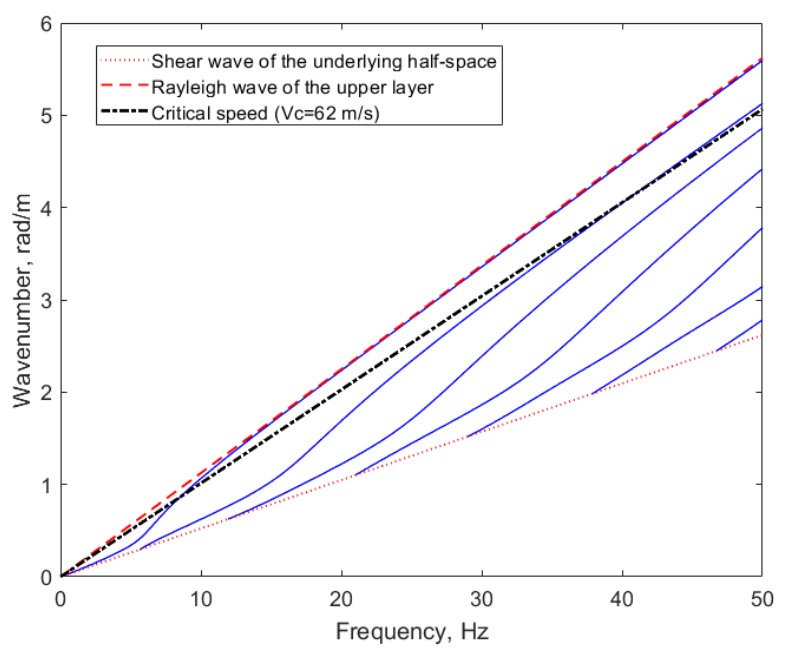

(a)

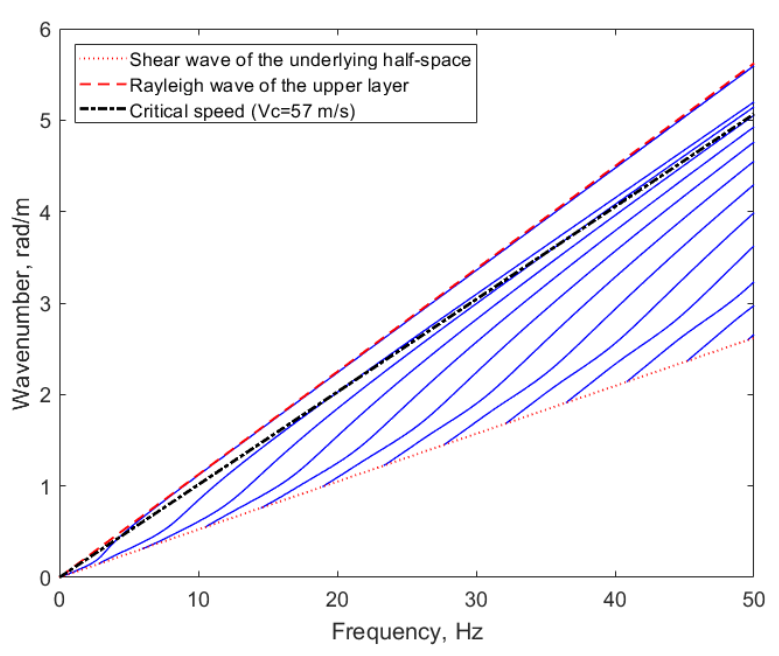

(b)

Figure 15 Dispersion diagrams for (a) case 6 (first layer depth $4 \mathrm{~m}$ ); (b) case 7 (8 m)

\subsection{Discussion}

In the previous sections, the resonance frequency has been estimated by three different methods. The results from these methods are compared in Fig. 16. The result obtained from the stationary harmonic load is independent of load speed, whereas the other two results vary with load speed. Nevertheless, the results obtained from the dispersion curves have generally good agreement with the results obtained from the spectrum of the response to a moving load and both results are similar to that obtained from the stationary harmonic load. For those results obtained for a load moving at speeds lower than the critical speed, it is difficult to identify the resonance peak. As a result, no resonance frequency is shown in Fig. 16 for these lower speeds.

The resonance frequency calculated from the dispersion curve can be identified at lower speeds than that from the spectrum of the moving load response. In most cases the result from the dispersion curve can be identified for speeds higher than the Rayleigh wave speed of the first layer. However, the resonance frequency has limited relevance for these speeds as the resonance phenomenon cannot be observed in the time history (see Figs 4 10). Furthermore, quite poor agreement is found between these two methods for speeds lower than the critical speed for cases 2-5. For case 5, the method based on the dispersion curves does not give a result above $70 \mathrm{~m} / \mathrm{s}$. This is due to the fact that the two layers have quite similar properties and the soil tends to become nearly non-dispersive (see Fig. 14(b)). 

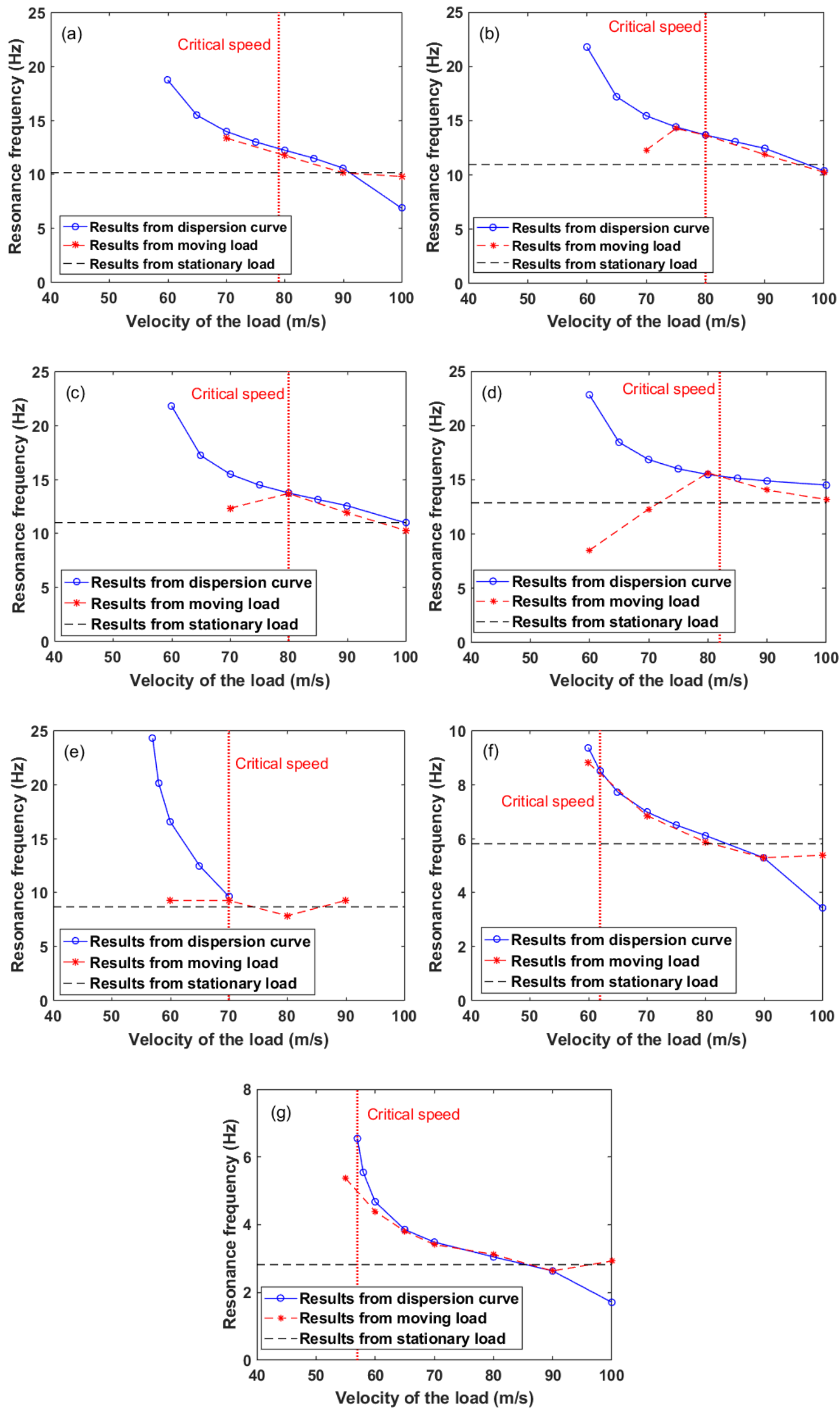

Figure 16 Resonance frequency at different load speeds obtained by using three different methods;

(a) case 1; (b) case 2; (c) case 3; (d) case 4; (e) case 5; (f) case 6; (g) case 7 
According to $[17,18]$, the resonance frequency can be calculated by

$$
f_{\text {res }}=\frac{c_{p 1}}{4 H}
$$

where, $c_{p 1}$ is the P-wave speed of the first layer and $H$ is the layer depth. The resonance frequency calculated from this formula is listed in Table 4. Differences of up to almost a factor of 3 can be found compared with the results from the present studies. Mezher et al. [12] give a modified formula

$$
f_{\text {res }}=\frac{c_{s 1}}{H}
$$

where, $c_{s 1}$ is the $\mathrm{S}$-wave speed of the first layer. As shown in Table 4, estimates based on this formula are all too high, by a factor of around $2 \sim 3$ times, compared with the resonance frequency calculated from the stationary harmonic load. A modified formula is suggested here to estimate the resonance frequency of a layered half-space:

$$
f_{\text {res }}=\frac{c_{s 1}}{2 H}
$$

Comparisons of the resonance frequency calculated based on Eq. (1) Eq. (3) with the results from the stationary harmonic load and the results at critical speed from the spectrum of the quasi-static responses are shown in Tables 5 and 6. The results from the quasi-static responses are used at the critical speed because a clear oscillation tail can be found in the time domain in each case. The results from the stationary harmonic load are used as it is the only method without speed dependence that can be easily calculated. Furthermore, it agrees well with the results from the quasi-static response at higher load speeds.

Significant differences can be found based on Eq. (2) compared with the two different methods. Better results are found based on Eq. (1); however, significant differences are found for cases 2 4, which include higher P- and S-wave speeds for the substratum. Using Eq. (3) differences of less than $50 \%$ are found compared with the results from stationary harmonic load, apart from case 5 for which a difference of around $67 \%$ is found. However, this case does not have a very distinct resonance (see Fig. 8) as the properties for the two layers are very similar. This situation is therefore quite similar to a homogeneous half-space, which is non-dispersive and does not have this resonance phenomenon (see Fig. 11). 
Table 4 Comparison of resonance frequency based on three different equations with the results from stationary harmonic load

\begin{tabular}{|c|c|c|c|c|c|}
\hline & $\begin{array}{c}\text { Results from } \\
\text { stationary } \\
\text { harmonic load }\end{array}$ & $\begin{array}{c}\text { Results at } V_{\text {cr }} \\
\text { from the spectrum } \\
\text { of quasi-static } \\
\text { response }\end{array}$ & $\begin{array}{c}\text { Based on } \\
\text { Eq. (1) }\end{array}$ & $\begin{array}{c}\text { Based on } \\
\text { Eq. (2) }\end{array}$ & $\begin{array}{c}\text { Based on } \\
\text { Eq. (3) }\end{array}$ \\
\hline Case 1 & $10 \mathrm{~Hz}$ & $12 \mathrm{~Hz}$ & $15 \mathrm{~Hz}$ & $30 \mathrm{~Hz}$ & $15 \mathrm{~Hz}$ \\
\hline Case 2 & $11 \mathrm{~Hz}$ & $14 \mathrm{~Hz}$ & $30 \mathrm{~Hz}$ & $30 \mathrm{~Hz}$ & $15 \mathrm{~Hz}$ \\
\hline Case 3 & $11 \mathrm{~Hz}$ & $14 \mathrm{~Hz}$ & $30 \mathrm{~Hz}$ & $30 \mathrm{~Hz}$ & $15 \mathrm{~Hz}$ \\
\hline Case 4 & $13 \mathrm{~Hz}$ & $15 \mathrm{~Hz}$ & $30 \mathrm{~Hz}$ & $30 \mathrm{~Hz}$ & $15 \mathrm{~Hz}$ \\
\hline Case 5 & $9 \mathrm{~Hz}$ & $9 \mathrm{~Hz}$ & $15 \mathrm{~Hz}$ & $30 \mathrm{~Hz}$ & $15 \mathrm{~Hz}$ \\
\hline Case 6 & $6 \mathrm{~Hz}$ & $8.5 \mathrm{~Hz}$ & $7.5 \mathrm{~Hz}$ & $15 \mathrm{~Hz}$ & $7.5 \mathrm{~Hz}$ \\
\hline Case 7 & $3 \mathrm{~Hz}$ & - & $3.75 \mathrm{~Hz}$ & $7.5 \mathrm{~Hz}$ & $3.75 \mathrm{~Hz}$ \\
\hline
\end{tabular}

Table 5 Difference between the results based on Eqs (1) to (3) and the results for a stationary harmonic load

\begin{tabular}{|l|c|c|c|}
\hline & Based on Eq. (1) & Based on Eq. (2) & Based on Eq. (3) \\
\hline Case 1 & $50 \%$ & $200 \%$ & $50 \%$ \\
\hline Case 2 & $173 \%$ & $173 \%$ & $36 \%$ \\
\hline Case 3 & $173 \%$ & $173 \%$ & $36 \%$ \\
\hline Case 4 & $131 \%$ & $131 \%$ & $15 \%$ \\
\hline Case 5 & $67 \%$ & $233 \%$ & $67 \%$ \\
\hline Case 6 & $25 \%$ & $150 \%$ & $25 \%$ \\
\hline Case 7 & $25 \%$ & $150 \%$ & $25 \%$ \\
\hline
\end{tabular}

Table 6 Difference between the results based on Eqs (1) to (3) and the results at $V_{c r}$ from the spectrum of quasi-static response

\begin{tabular}{|l|c|c|c|}
\hline & Based on Eq. (1) & Based on Eq. (2) & Based on Eq. (3) \\
\hline Case 1 & $25 \%$ & $150 \%$ & $25 \%$ \\
\hline Case 2 & $114 \%$ & $114 \%$ & $7 \%$ \\
\hline Case 3 & $114 \%$ & $114 \%$ & $7 \%$ \\
\hline Case 4 & $100 \%$ & $100 \%$ & $0 \%$ \\
\hline Case 5 & $67 \%$ & $233 \%$ & $67 \%$ \\
\hline Case 6 & $-12 \%$ & $76 \%$ & $-12 \%$ \\
\hline Case 7 & $25 \%$ & $150 \%$ & $25 \%$ \\
\hline
\end{tabular}

Comparing the results from Eq. (3) with those from the quasi-static response at the critical speed, see Table 6, better agreement is found, with differences of less than $25 \%$ apart from case 5 . Note that none of the formulae mentioned above consider any speed dependence. Therefore, they are inevitably approximations. Nevertheless, Eq. (3) tends to give better agreement compared with the results from the stationary harmonic load and the quasi-static load. 


\section{Conclusions}

A parametric study of the resonant characteristic of a load moving on a layered half-space has been carried out. Simulations have been performed using a range of ground properties to show the dependence of the critical speed and the resonance frequency of the track/ground system on the wave speeds of the upper layer and underlying half-space and the layer depth.

The critical speed is shown to be independent of the P-wave speeds of either layer. On the other hand, it decreases when the S-wave speed of the second layer is reduced, showing the importance of ground layering. When the layer depth is increased, the critical speed also decreases. It reduces by around $25 \%$ when the layer depth is increased from $2 \mathrm{~m}$ to $4 \mathrm{~m}$ for the current parameters. However, much smaller differences are found when it is increased further.

The resonance frequency of the layered ground is studied using three methods. From results due to a moving point load, it is found to be influenced by the speed of the moving load and tends to decrease when the load speed increases. Changes to the P-wave speed for the upper layer and the half-space and the S-wave speed for the half-space have a minimal effect on the resonance frequency. Larger differences are found when the depth of the first layer is changed. A much clearer oscillation behind the load can be found with a stiffer top layer and shallow layer depth, especially when the load speed is close to the critical speed. Furthermore, a longer oscillation in the time domain is found when the difference between the S-wave speeds of the two layers becomes significant.

The dispersion curve is almost the same at low frequency whether the track is included on the ground or not. Therefore, for calculating the resonance frequency, the track can be neglected. It is expected that the oscillation behind the load occurs when the load speed is higher than the Rayleigh wave speed of the first layer, due to the fact that the waves start to propagate in this layer. However, for some cases, no oscillation is found behind the load in the time domain even though the load speed is higher than the surface wave speed.

The resonance frequency obtained from the moving point load and the dispersion curve are similar. The resonance frequency estimated from the results for a stationary harmonic load applied on the track/ground model give a good approximation even though the results are influenced in practice by the speed of the moving load.

Based on the present study, the resonance frequency of a layered ground is shown to be related to the S-wave speed and the depth of the first layer, not the P-wave speed. Consequently, an 
approximate formula is proposed, which gives results within $25 \%$ of the results from the spectrum of quasi-static response at the critical speed.

This resonance-like phenomenon should be taken into account in high-speed railway design. Based on the present study, in order to avoid this resonance-like phenomenon, it is suggested that the design train speed should be not only lower than the critical speed but also less than the shear wave speed of the first layer of the ground. Care should also be taken to avoid the coincidence of dominant train-load frequencies and the ground resonance frequency.

Although the rail receptance from a stationary harmonic load does not account for the effect of load speed, it can still capture this resonance frequency relatively well. Furthermore, this result can be easily obtained using hammer tests in the field. As a result, based on the present study, the proposed formula has the potential to capture the main characteristics of the soil.

\section{Acknowledgements}

The work described here has been supported by the EPSRC under the programme grants EP/H044949/1, 'Railway Track for the $21^{\text {st }}$ Century (Track 21)' and EP/M025276/1, 'The science and analytical tools to design long life, low noise railway track systems (Track to the Future)'.

\section{References}

[1] Sheng X, Jones CJC, Petyt M. Ground vibration generated by a load moving along a railway track. J. Sound Vib. 1999;228:129-156.

[2] Fryba L. Vibration of Solids and Structures Under Moving Loads. Third edit. London: Thomas Telford; 1999.

[3] Dieterman HA, Metrikine VA. Steady state displacements of a beam on an elastic half space due to a uniformly moving load. Eur. J. Mech. - A/Solids. 1997;16:295-306.

[4] Lieb M, Sudret B. A fast algorithm for soil dynamics calculations by wavelet decomposition. Arch. Appl. Mech. 1998;68:147-157.

[5] Sheng X, Jones CJC, Petyt M. Ground vibration generated by a harmonic load acting on a railway track. J. Sound Vib. 1999;225:3-28.

[6] Madshus C, Kaynia AM. High-speed railway lines on soft ground: dynamic behaviour at critical train speed. J. Sound Vib. 2000;231:689-701.

[7] Kaynia AM, Madshus C, Zackrisson P. Ground vibration from high-speed trains: prediction and countermeasure. J. Geotech. Geoenvironmental Eng. 2000;126:531-537.

[8] Lane H, Berg S, Larsson M. Finite element calculations of rail vibration countermeasures. Veh. Syst. Dyn. 2007;45:565-581.

[9] Costa PA, Colaço A, Calçada R, et al. Critical speed of railway tracks. Detailed and simplified approaches. Transp. Geotech. 2015;2:30-46.

[10] Sheng X, Jones CJC, Thompson DJ. A theoretical study on the influence of the track on train-induced ground vibration. J. Sound Vib. 2004;272:909-936. 
[11] Dieterman HA, Metrikine A. The equivalent stiffness of a half-space interacting with a beam. critical velocities of a moving load along the beam. Eur. J. Mech. A/Solids. 1996;15:67-90.

[12] Mezher SB, Connolly DP, Woodward PK, et al. Railway critical velocity - Analytical prediction and analysis. Transp. Geotech. 2015;6:84-96.

[13] Costa PA, Calçada R, Cardoso AS, et al. Influence of soil non-linearity on the dynamic response of high-speed railway tracks. Soil Dyn. Earthq. Eng. 2010;30:221-235.

[14] Shih JY, Thompson DJ, Zervos A. The influence of soil nonlinear properties on the track/ground vibration induced by trains running on soft ground. Transp. Geotech. 2017;11.

[15] Milne DRM, Le Pen LM, Thompson DJ, et al. Properties of train load frequencies and their applications. J. Sound Vib. 2017;397:123-140.

[16] Shih JY, Thompson DJ, Zervos A. The effect of boundary conditions, model size and damping models in the finite element modelling of a moving load on a track/ground system. Soil Dyn. Earthq. Eng. 2016;89.

[17] El Kacimi A, Woodward PK, Laghrouche O, et al. Time domain 3D finite element modelling of train-induced vibration at high speed. Comput. Struct. 2013;118:66-73.

[18] Kouroussis G, Connolly DP, Verlinden O. Railway-induced ground vibrations - a review of vehicle effects. Int. J. Rail Transp. 2014;2:69-110.

[19] Yang YB, Hung HH, Chang DW. Train-induced wave propagation in layered soils using finite/infinite element simulation. Soil Dyn. Earthq. Eng. 2003;23:263-278.

[20] Haskell NA. The dispersion of surface waves on multilayered media. Bull. Seismol. Soc. Am. 1953;43:17-34.

[21] Thomson WT. Transmission of elastic waves through a stratified solid medium. J. Appl. Phys. 1950;21:89.

[22] Auersch L. Mitigation measures for ballasted tracks - sleepers, sleeper pads and substructure - Results from the finite element boundary element method. In B. Faure and E. Bongini, RIVAS Deliverable D3.2, 2012. 